\title{
BMJ Open Quality Improving cardiac operating room to intensive care unit handover using a standardised handover process
}

\author{
Yehoshua Gleicher, ${ }^{1,2}$ Jeffrey David Mosko, ${ }^{2,3}$ Irene McGhee ${ }^{4}$
}

To cite: Gleicher Y, Mosko JD, McGhee I. Improving cardiac operating room to intensive care unit handover using a standardised handover process.BMJ Open Quality 2017;6:e000076. doi:10.1136/ bmjoq-2017-000076

Received 3 April 2017 Revised 27 August 2017 Accepted 16 September 2017

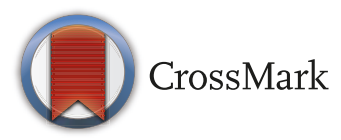

${ }^{1}$ Department of Anesthesia, Mount Sinai Hospital, Toronto, Ontario, Canada

${ }^{2}$ Institute of Health Policy, Management and Evaluation, Toronto, Ontario, Canada ${ }^{3}$ Department of Medicine, St. Michael's Hospital, Toronto, Ontario, Canada

${ }^{4}$ Department of Anesthesia, Sunnybrook Health Sciences Centre, Toronto, Ontario, Canada

Correspondence to

Dr Yehoshua Gleicher;

josh.gleicher@mail.utoronto.ca

\section{ABSTRACT}

Handovers from the cardiovascular operating room (CVOR) to the cardiovascular intensive care unit (CVICU) are complex processes involving the transfer of information, equipment and responsibility, at a time when the patient is most vulnerable. This transfer is typically variable in structure, content and execution. This variability can lead to the omission and miscommunication of critical information leading to patient harm. We set out to improve the quality of patient handover from the CVOR to the CVICU by introducing a standardised handover protocol. This study is an interventional time-series study over a 4-month period at an adult cardiac surgery centre. A standardised handover protocol was developed using quality improvement methodologies. The protocol included a handover content checklist and introduction of a formal 'sterile cockpit' timeout. Implementation of the protocol was refined using monthly iterative Plan-Do-Study-Act. The primary outcome was the quality of handovers, measured by a Handover Score, comprising handover content, teamwork and patient care planning indicators. Secondary outcomes included handover duration, adherence to the standardised handover protocol and handover team satisfaction surveys.

37 handovers were observed (6 pre intervention and 31 post intervention). The mean handover score increased from 6.5 to 14.0 (maximum 18 points). Specific improvements included fewer handover interruptions and more frequent postoperative patient care planning. Average handover duration increased slightly from 2:40 to 2:57 min. Caregivers noted improvements in teamwork, content received and patient care planning. The majority (>95\%) agreed that the intervention was a valuable addition to the CVOR to CVICU handover process. Implementation of a standardised handover protocol for postcardiac surgery patients was associated with fewer interruptions during handover, more reliable transfer of critical content and improved patient care planning.

\section{PROBLEM AND BACKGROUND}

Effective and comprehensive patient care handovers are critical for patient safety. Weak handover processes have been identified as contributing causes for adverse events and patient harm. ${ }^{1-4}$ Specifically, failure to communicate intraoperative events to the postoperative management team can result in 'inappropriate monitoring of patients postoperatively, absence of enhanced vigilance for specific, predictable postoperative complications, and medication errors'. ${ }^{5}$ Furthermore, poor postoperative handovers lead to incorrect treatment plans, diagnostic delays, patient complaints, increased length of stay and increased mortality. ${ }^{67}$

Postcardiac surgery patients have been shown to be especially vulnerable to the negative consequences resulting from poor postoperative handovers. ${ }^{8}$ This is not surprising given the morbidity of the patients, higher baseline mortality rate and surgical complexity. Studies evaluating postcardiac surgery handovers noted that important content items are omitted $>50 \%$ of the time. ${ }^{910}$ As a result, cardiac surgery guidelines from the American Heart Association highlighted postcardiac surgery handover failures as a significant source of medical errors and recommend handover improvement using standardised handover protocols. ${ }^{8}$

Despite compelling evidence that poor postoperative handovers contribute to patient morbidity, handovers for elective and emergent surgical cases remain inconsistent and incomplete. In an observational study at our centre, physician-to-physician postoperative handovers were received in only $4 \%$ of elective surgery patients transferred from the postoperative care unit to the critical care unit. Even more concerning was the fact that in $17 \%$ of the total cases important information relevant to postoperative patient management and resuscitation was not communicated to the critical care team. ${ }^{11}$

Contributing factors to poor postoperative handovers include inconsistent perioperative team attendance, lack of handover structure and documentation, and interruptions and distractions throughout the handover process. ${ }^{72}$ Proposed solutions to improving postoperative handover quality include implementing standardised handover protocols. Studies using such protocols have yielded promising results in the paediatric cardiac surgery settings. ${ }^{9} 1013-15$ We set out 
to improve our post adult cardiac surgery handover process by developing and implementing a standardised handover protocol.

\section{DESIGN}

Our study is a prospective time-series quality improvement (QI) study conducted in the cardiovascular intensive care unit (CVICU) of a tertiary care centre. The patient population included all patients undergoing elective or emergent cardiac surgeries. Operating room (OR) and CVICU team member rotations meant that it was not feasible to randomise teams to intervention and non-intervention groups. Formal ethical approval was not required as per our centre's guidelines for QI projects of this nature.

\section{MEASUREMENT}

A single observer, not part of the handover team, and experienced in anaesthesiology and critical care, was present for handovers based on availability. The primary outcome of our intervention was the quality of handovers, measured by the total handover score. The handover scoring system assessed components of handover content and structure which were deemed critical for the CVICU team to be able to care for the patient in a safe and competent manner. This scoring system was developed based on items identified in the literature as well as items identified by the project team as part of our initial root-cause-analysis. ${ }^{1013-17}$

The handover score was evaluated based on three dimensions: handover content, teamwork and patient care planning (online supplementary appendix 1 ). The handover content dimension included a succinct review of patient comorbidities, presenting illness, surgical procedure (as described by the surgeon) and ongoing patient management such as ongoing resuscitation, invasive monitoring, ventilation and haemodynamic support. The handover teamwork dimension score comprised the absence of handover interruptions and the CVICU physician's readback summary. A handover interruption was defined as any non-emergent event distracting the attention of a handover team member from the handover process, such as multitasking or the transfer of equipment. We defined the receiving physician's readback as a brief verbal summary describing any ongoing patient medical/ surgical issues, in a close-loop communication format. Lastly, the patient care planning dimension focused on whether the handover team discussed appropriateness for our targeting 'early' extubation within 6hours of surgery, as well as the formulation of management and contingency planning for ongoing medical issues.

Adherence to our intervention was assessed through a number of process measures. First, we recorded whether the handover team entered a sterile cockpit environment for the verbal handover. Second, we measured whether our new handover documentation checklist was being used as intended for transfer of content. Finally, we tracked whether the anaesthesiologists were documenting the handover content using our handover checklist.

Balance measures included handover duration and handover team surveys, and focused on ensuring that our intervention did not introduce any inadvertent harm. This was of particular importance in our patient population as they are vulnerable post-cardiopulmonary bypass and an overly prolonged handover process could potentially result in patient harm. The overall duration of handover was recorded and defined as the duration from the moment the initial timeout commenced, to the final readback by the receiving physician. We surveyed satisfaction rates of both OR and CVICU teams on the various aspects of our intervention. This provided further feedback and suggestions used to generate further improvement to our handover process, and alerted our team to any potential unintended and unanticipated consequences noted by front-line workers.

We estimated that observing approximately 30 handovers would provide a representative sample. No formal power analysis was performed. Statistical process control charts were used to analyse our data and track potential improvement generated by our intervention. For final statistical analysis, group means were compared using unpaired t-test. For all analyses, statistical significance was defined by a two-sided $\mathrm{p}<0.05$.

\section{STRATEGY}

The intervention for this improvement project was a standardised handover protocol. The goal of the protocol was to improve the effectiveness of information transfer during patient handover. The handover improvement initiative was led by a team of physicians and nurses, and included representatives from anaesthesiology, cardiac surgery and critical care. The protocol content was developed based on an extensive review of up-to-date postoperative handover literature, as well as feedback from frontline workers derived from inventive problem-solving methodology. ${ }^{18}$

Handover strategies identified in the literature and adopted into our protocol included face-to-face communication, optimising both OR and CVICU team attendance during handover, limiting interruptions, having the outgoing team develop contingency planning and documentation of the handover content. Furthermore, there was significant evidence recommending the use of an item checklist, and this strategy was incorporated into our protocol as well. ${ }^{1013-17}$

The standardised handover protocol included two key components:

- Streamlined process

On patient arrival to the CVICU, the patient was connected to the mechanical ventilator. The handover team then entered a 'sterile cockpit'-like environment and performed a formal timeout. Introductions were made to improve ad hoc teamwork and ensure complete handover team attendance. The Anaesthesia As- 


\section{CVOR to CVICU Transition Note}

1. INTRODUCTIONS (all team members present)

2. PATIENT IDENTIFICATION (name band \& allergies noted)

3. INFECTION PRECAUTIONS no/yes

4. PROCEDURE DETAILS (described by surgeon) elective / urgent on / off pump
PATIENT IDENTIFYING INFORMATION

5. COMORBIDITIES

6. INTRAOPERATIVE COURSE

(Intubation, ventilation, monitoring/lines, separation from CPB)

7. STATUS POST CPB

\begin{tabular}{|l|l|l|l|}
\hline Pump time & & Separation from CPB & \\
\hline Last HGB & & Blood Products Transfused & \\
\hline Coagulation & & \multicolumn{2}{|l|}{} \\
\hline Vasoactive Agents & \multicolumn{2}{|l|}{} \\
\hline Pacing Requirements & Yes/no & TEE findings postop & \\
\hline
\end{tabular}

8. CVOR NURSING / PERFUSION ISSUES

9. EARLY EXTUBATION CANDIDATE

yes / no if no please indicatereason:囯Complicated $O R$ [?Poor general status [Difficult AW ?Respiratory

10. ANTICIPATED EVENTS (graft/valve, PTX, tamponade, hemostasis, AKI, arrhythmias, stroke, vasoplegia)

b.

11. READBACK OF OUTSTANDING ISSUES BY PHYSICAN \& NURSE

Sign OFF at (date and time)

Figure 1 Postcardiac surgery handover checklist and documentation tool. CVICU, cardiovascular intensive care unit; CVOR, cardiovascular operating room.

sistant was then charged with monitoring the patient while the rest of the clinicians were free to communicate without interruption. Non-essential tasks (ie, organising infusion pumps, moving lines and tubes, attending non-emergent issues regarding other patients) were not permitted throughout the handover process. The timeout was concluded by an opportunity for any team member to ask questions, followed by a readback outlining ongoing medical/surgical issues and a review of contingency plans.

- Information checklist and documentation

A combined checklist and documentation tool (figure 1) outlining the information components to be discussed during handover was used to aid in the verbal transfer of information. This documentation sheet was to be filled out by the anaesthesia team. It became part of the patient chart, thus enabling clinicians caring for the patient later in the day (not present during the handover) to review critical patient information and patient care planning at a glance. The checklist also included a component requiring the surgeon to briefly describe the procedure performed, any surgical difficulties or unexpected events encountered, and postoperative surgical concerns.

In order to address any gaps in handover team adherence to our intervention, the study used the iterative capability of Plan-Do-Study-Act (PDSA) cycles. Through the use of PDSA cycles, the information collected was reviewed on a monthly basis by the project team. Protocol compliance was monitored via process measures described above and enhanced using the lessons learnt and change ideas derived from this information (table 1). The PDSA model also helped ensure that change ideas derived from similar handover studies were adapted successfully to our local setting.

\section{RESULTS}

The postcardiac surgery standardised handover protocol was launched in September 2013. Data collection and 
Table 1 A review of the Plan-Do-Study-Act (PDSA) cycles used to implement the standardised handover protocol

\begin{tabular}{|c|c|c|c|c|}
\hline PDSA & Plan & Do & Study & Act \\
\hline Cycle \#1 & $\begin{array}{l}\text { Implement new handover } \\
\text { protocol }\end{array}$ & $\begin{array}{l}\text { Handover protocol } \\
\text { implemented } \\
\text { throughout } \\
\text { September/ } \\
\text { October } 2013\end{array}$ & $\begin{array}{l}\text { Checklist used effectively } \\
\text { with improvement in content } \\
\text { communicated } \\
\text { Confusion of CVICU nursing } \\
\text { over which equipment is } \\
\text { connected on patient arrival } \\
\text { Difficulty of anaesthesiologist } \\
\text { to concurrently use checklist } \\
\text { and monitor patient }\end{array}$ & $\begin{array}{l}\text { New guideline in handover } \\
\text { protocol that only } \\
\text { mechanical ventilation be } \\
\text { connected prior to entering } \\
\text { sterile cockpit } \\
\text { Anaesthesia assistant } \\
\text { designated as responsible } \\
\text { for patient monitoring, } \\
\text { anaesthesiologist will focus } \\
\text { on handover }\end{array}$ \\
\hline Cycle \#2 & $\begin{array}{l}\text { Continue handover } \\
\text { protocol use } \\
\text { Revise equipment } \\
\text { connection sequence and } \\
\text { patient monitoring }\end{array}$ & $\begin{array}{l}\text { Handover protocol } \\
\text { continued } \\
\text { throughout } \\
\text { November } 2013\end{array}$ & $\begin{array}{l}\text { Observed smoother } \\
\text { equipment transition and } \\
\text { entering sterile cockpit } \\
\text { CVICU team often waiting } \\
\text { too long for patient arrival } \\
\text { A few late adopters were still } \\
\text { not using handover protocol }\end{array}$ & $\begin{array}{l}\text { Anaesthesia assistant } \\
\text { designated as responsible } \\
\text { for patient monitoring, } \\
\text { anaesthesiologist will focus } \\
\text { on handover } \\
\text { Encourage late adopters to } \\
\text { use handover protocol } \\
\text { OR team to notify CVICU } \\
5 \text { min prior to patient arrival }\end{array}$ \\
\hline Cycle \#3 & $\begin{array}{l}\text { Ensure OR team notifies } \\
\text { ICU of patient arrival in a } \\
\text { timely manner } \\
\text { Sustain gains made by } \\
\text { handover protocol }\end{array}$ & $\begin{array}{l}\text { Handover protocol } \\
\text { refinement and } \\
\text { use continued } \\
\text { throughout } \\
\text { December } 2013\end{array}$ & $\begin{array}{l}\text { Reduction of CVICU team } \\
\text { waiting for patient and OR } \\
\text { team arrival } \\
\text { Feedback from CVICU team } \\
\text { requesting incorporating } \\
\text { handover the documentation } \\
\text { to the CVICU admission note }\end{array}$ & $\begin{array}{l}\text { Handover documentation } \\
\text { appended to CVICU } \\
\text { admission note after } \\
\text { approval from institution } \\
\text { forms committee }\end{array}$ \\
\hline
\end{tabular}

CVICU, cardiovascular intensive care unit; CVOR, cardiovascular operating room; ICU, intensive care unit; OR, operating room.

PDSA cycles were conducted over 4 months with a total of 37 handovers observed during this time period. To reduce bias due to variability in communication skills, we ensured that each cardiac anaesthesiologist was observed providing a handover at least twice during the study period.

A total of 6 preintervention and 31 postintervention handovers were observed throughout the study period. Following implementation of our intervention, the mean handover score increased from 6.5 to 14.0 by an average value of 7.5 ( $\mathrm{p}=0.001,95 \%$ CI 5.8 to 9.2$)$. Specifically, improvements noted were the reduction of handover interruptions and improved postoperative patient care planning and contingency planning for ongoing medical and surgical issues (table 2). Figure 2 illustrates the handover score improvement generated by the intervention throughout the observed period.

Table 2 A summary of the outcome, process and balance measure results evaluating the standardised handover protocol

\begin{tabular}{|c|c|c|c|}
\hline & Preintervention & Postintervention & p Value \\
\hline \multicolumn{4}{|l|}{ Outcome measures } \\
\hline Handovers observed (unpaired t-test) & 6 & 31 & \\
\hline Mean handover score (out of 18 ) & 6.5 & 14.0 & 0.001 \\
\hline$\%$ of handovers with interruptions & $66 \%(4 / 6)$ & $13 \%(4 / 31)$ & 0.013 \\
\hline $\begin{array}{l}\% \text { of handovers with patient care planning and contingency } \\
\text { planning }\end{array}$ & $16 \%(1 / 6)$ & $87 \%(27 / 31)$ & 0.002 \\
\hline Mean number of major content omissions (out of 14 items) & 9.2 & 3.2 & 0.001 \\
\hline \multicolumn{4}{|l|}{ Process measures } \\
\hline$\%$ of handovers using handover checklist & $\mathrm{N} / \mathrm{A}$ & $81 \%(25 / 31)$ & N/A \\
\hline$\%$ of handovers using formal timeout (sterile cockpit environment) & N/A & $97 \%(30 / 31)$ & N/A \\
\hline \multicolumn{4}{|l|}{ Balancing measures } \\
\hline Mean handover duration (min) & $2: 40$ & $2: 57$ & 0.344 \\
\hline
\end{tabular}



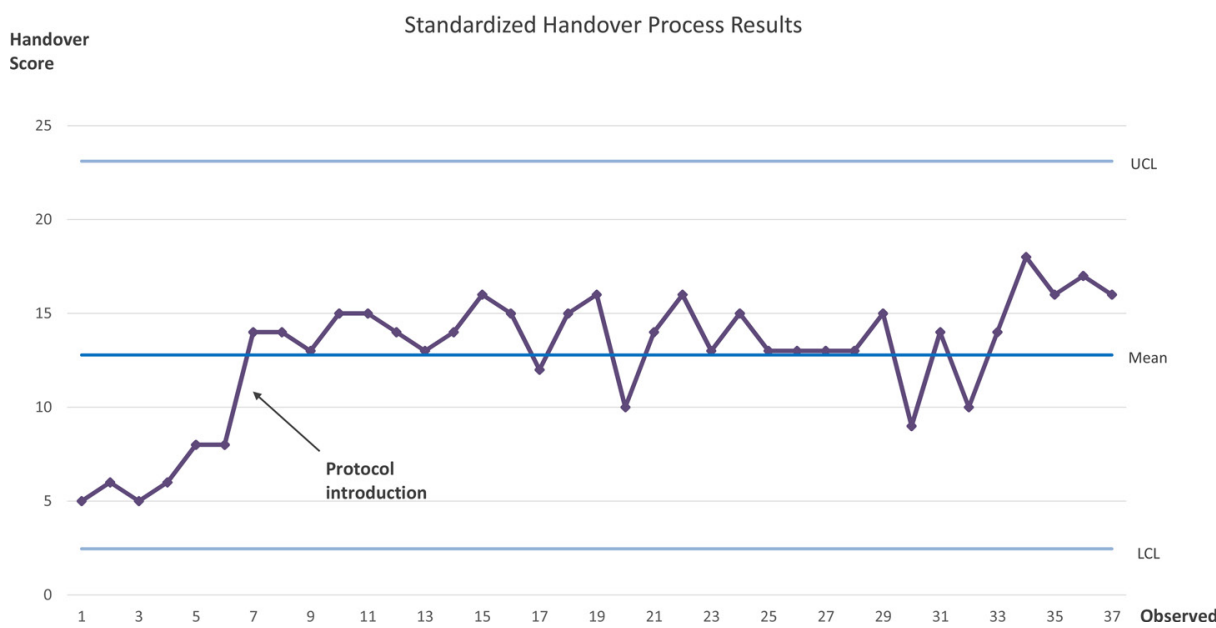

Figure 2 A statistical process control chart illustrating the handover scores observed for each handover before and after implementation of the standardised handover protocol.LCL, lowercontrol limit; UCL, uppercontrol limit.

As with any QI intervention, user adherence to our intervention was imperative. In total, three PDSA cycles were completed throughout the study period, in part to help maximise user adherence. Table 1 outlines each PDSA cycle including iterative modifications made to our handover intervention using PDSA data.

No unexpected harm resulted from the introduction of the standardised handover protocol. Handover duration increased marginally from $2: 40 \mathrm{~min}$ to $2: 57 \mathrm{~min}$ $(\mathrm{p}=0.344)$. Thirty-six surveys were collected with feedback from members of the cardiac team participating in the handover initiative. These caregivers noted improvements in teamwork, content received and patient care planning. The vast majority ( $>95 \%)$ agreed that the intervention was a valuable addition to the CVOR to CVICU handover process (table 3 ).

\section{LESSONS AND LIMITATIONS}

There is mounting evidence linking effective patient handovers to medical error prevention. ${ }^{18} 16$ It follows that there is growing support for implementing standardised

\section{Table 3 A summary of the handover team survey results}

Question

$\%$ that

agreed

The new standardised handover process improved 91 the quality of information transferred during handover

The new standardised handover process 91

improved teamwork between operating room and cardiovascular intensive care unit team members

The new standardised handover process interfered 3 with caregivers' ability to provide timely patient focused care

Overall, the standardised handover process is a 97 valuable addition to the cardiac surgery programme

A total of 36 nurses, anaesthesiologists and critical care specialists were surveyed regarding the new standardised handover protocol. handover processes for patient care transfers across various medical settings. This is especially true for patients at higher risk for medical errors, such as perioperative and ICU patients. ${ }^{219}$ This study was therefore aimed to develop and implement a robust handover protocol for patients transitioning from the cardiac OR to the CVICU. Direct communication, minimising interruptions and multitasking, discussion of anticipated events and contingency plans, and documentation of critical content were the key elements of the protocol. Using our intervention protocol, we were able to significantly improve the quality of handovers with minimal increase in handover duration.

Ideally, we would have liked to demonstrate direct improvement in patient outcome variables such as inpatient mortality or ICU length-of-stay (LOS). But with local adult cardiac surgery mortality rates of $2 \%-4 \%$ and ICU LOS being dependent on a number of other medical and logistical factors, our study was underpowered and unable to examine such patient outcomes. ${ }^{20}$

Review of the previous literature identified critical elements which we were able to adapt and apply in the development and implementation phases of our study. ${ }^{9} 1314$ Specifically, the use of a checklist to ensure handover content completeness, and the principle of a 'sterile cockpit' environment to minimise distractions were adopted and adapted to our centre's culture. These elements were well received by handover team members, as evident by front-line worker surveys indicating perceived improved teamwork and transfer of content.

One of the major goals of our handover protocol was the reduction of handover content variability. This was accomplished by introducing structure and sequence to the handover process as illustrated by the handover checklist and documentation tool. Previous studies have specifically targeted reducing handover variability with similar positive results. Zavalkoff and colleagues introduced a handover information transfer tool for paediatric cardiac surgery patients, which intended to reduce handover 
content variability. ${ }^{13}$ They derived this concept from Six Sigma literature and emphasised that by reducing variability they were able to reduce the chance of error (ie, information omissions).

There are several implementation challenges that need to be considered when attempting to improve the postoperative handover process through standardisation. The transferability and sustainability of the interventions described above need to be taken into consideration. Surgical centres may have differing team structures, postoperative care units and resources. Being well aware of this obstacle, our study used PDSA cycles to facilitate iterative improvement of the handover protocol. Joy et al reported similar effectiveness of PDSA cycles to finetune their intervention, which in turn led to a reduction in handover technical errors and content omissions. ${ }^{10}$ Other studies have used various methods to adapt handover protocols to their local settings. Such strategies included surveying front-line workers and forming multidisciplinary handover protocol development teams. ${ }^{9} 13$ In order to overcome local implementation barriers, we recommend the use of such QI framework methodologies when developing and disseminating standardised handover protocols.

Similar to our effective use of PDSA cycles, our study benefited from direct contribution of front-line workers in the protocol design and refinement using feedback from team surveys. This provided stakeholders with a sense of ownership for the new handover process, which greatly contributed to protocol adherence.

There are a number of limitations to our study. First, a single observer was used to collect handover data. To minimise any observer-expectancy bias, definitions for handover data collected were outlined ahead of time. Second, having the data collected in real time could potentially introduce an observer effect (Hawthorne effect), thereby changing the behaviour of the handover team in a positive manner. Despite the Hawthorne effect being completely unavoidable, it was our belief that given the frequent number of handovers in our CVICU, the use of the handover protocol was not greatly impacted by observation. Third, we were able to collect a relatively small amount of preintervention data due to resource allocation constraints. That said, the findings of the preintervention handovers observed were consistent and homogenous, and revealed deficiencies in handover content and patient care planning. Lastly, our intervention was based in a single inpatient unit at our institution and therefore the external validity of our results may not be generalisable to other settings.

Sustainability is a crucial component of any QI project of this nature. Since completion of our QI project, handovers from the cardiac surgery OR to the CVICU have continued to use our intervention with high a compliance rate of $>95 \%$. The handover protocol has since then become standard practice for cardiac surgery cases at our institution. A key reason for this has been the high satisfaction rates by both the OR and CVICU teams. Furthermore, based on positive feedback from the CVICU team and continuous iterative improvement, the handover documentation form seen in figure 1 has been appended to the CVICU physician admission note and has become integral part of the patient's medical record.

\section{CONCLUSION}

Handovers following cardiac surgery are a complex process occurring in settings characterised by frequent interruptions and unstructured information transfer. In this QI study, implementation of a handover protocol led to fewer interruptions during handover, more reliable transfer of critical content and improved patient care planning. Ensuring seamless transitions of care between healthcare providers is critical to patient safety and can be enabled by the use of standardised comprehensive handover processes.

Acknowledgements The authors acknowledge Dr Fuad Moussa and Pamela Meyer for their contributions in helping implement this project.

Contributors YG helped design the study, collect the data, analyse the data and helped write the first draft of the manuscript. JDM helped prepare the manuscript. IMcG helped design the study, analyse the data and helped write the first draft of the manuscript.

Funding This study was funded by the Sunnybrook Health Sciences Center Department of Anesthesia and the Canadian Patient Safety Institute.

Competing interests None declared.

Provenance and peer review Not commissioned; externally peer reviewed.

Open Access This is an Open Access article distributed in accordance with the Creative Commons Attribution Non Commercial (CC BY-NC 4.0) license, which permits others to distribute, remix, adapt, build upon this work non-commercially, and license their derivative works on different terms, provided the original work is properly cited and the use is non-commercial. See: http://creativecommons.org/ licenses/by-nc/4.0/

(C) Published by the BMJ Publishing Group Limited. For permission to use (where not already granted under a licence) please go to http://www.bmj.com/company/ products-services/rights-and-licensing/

\section{REFERENCES}

1. Starmer AJ, Sectish TC, Simon DW, et al. Rates of medical errors and preventable adverse events among hospitalized children following implementation of a resident handoff bundle. JAMA 2013;310:2262.

2. Institute of Medicine (US) Committee on Quality of Health Care in America. In: Kohn LT, Corrigan JM, Donaldson MS, eds. To err is human: building a safer health system. Washington (DC): National Academies Press (US), 2000.

3. Kitch BT, Cooper JB, Zapol WM, et al. Handoffs causing patient harm: a survey of medical and surgical house staff. Jt Comm J Qual Patient Saf 2008;34:563-70.

4. Greenberg CC, Regenbogen SE, Studdert DM, et al. Patterns of communication breakdowns resulting in injury to surgical patients. $J$ Am Coll Surg 2007;204:533-40.

5. WHO surgical safety checklist and implementation manual. http:// www.who.int/patientsafety/safesurgery/ss_checklist/en/ (accessed 9 Mar 2017).

6. Lingard L, Espin S, Whyte S, et al. Communication failures in the operating room: an observational classification of recurrent types and effects. Qual Saf Health Care 2004;13:330-4.

7. Nagpal K, Vats A, Ahmed K, et al. An evaluation of information transfer through the continuum of surgical care: a feasibility study. Ann Surg 2010;252:402-7.

8. Wahr JA, Prager RL, Abernathy JH, et al. Patient safety in the cardiac operating room: human factors and teamwork: a scientific statement from the American heart association. Circulation 2013;128:1139-69.

9. Chen JG, Wright MC, Smith PB, et al. Adaptation of a postoperative handoff communication process for children with heart disease: a quantitative study. Am J Med Qual 2011;26:380-6. 
10. Joy BF, Elliott E, Hardy C, et al. Standardized multidisciplinary protocol improves handover of cardiac surgery patients to the intensive care unit. Pediatr Crit Care Med 2011;12:304-8.

11. D'Empaire PP, Coburn N, Amaral AC. Frequency and quality of handover between the operating room and the intensive care unit. Am J Respir Crit Care Med 2012;185:A5079.

12. Nagpal K, Abboudi M, Fischler L, et al. Evaluation of postoperative handover using a tool to assess information transfer and teamwork. Ann Surg 2011;253:831-7.

13. Zavalkoff SR, Razack SI, Lavoie J, et al. Handover after pediatric heart surgery: a simple tool improves information exchange. Pediatr Crit Care Med 2011;12:309-13.

14. Catchpole KR, de Leval MR, McEwan A, et al. Patient handover from surgery to intensive care: using formula 1 pit-stop and aviation models to improve safety and quality. Paediatr Anaesth 2007; $17: 470-8$.

15. Kaufmnan J, Twite M, Barrett $\mathrm{C}$, et al. A handoff protocol from the cardiovascular operating room to cardiac ICU is associated with improvements in care beyond the immediate postoperative period. $J t$ Comm J Qual Patient Saf 2013;39:306-AP1.

16. Segall N, Bonifacio AS, Schroeder RA, et al. Can we make postoperative patient handovers safer? a systematic review of the literature. Anesth Analg 2012;115:102-15.

17. Patterson ES, Roth EM, Woods DD, et al. Handoff strategies in settings with high consequences for failure: lessons for health care operations. Int J Qual Health Care 2004;16:125-32.

18. LariSemnani B, Mohebbi Far R, Shalipoor E, et al. Using creative problem solving (TRIZ) in improving the quality of hospital services. Glob J Health Sci 2014;7:7.

19. Baker GR, Norton PG, Flintoft V, et al. The Canadian adverse events study: the incidence of adverse events among hospital patients in Canada. CMAJ 2004;170:1678-86.

20. Cardiac Care Network. Report on adult cardiac surgery in Ontario. 2012. http://www.ccn.on.ca/ccn_public/uploadfiles/files/ Provincial\%20Cardiac\%20Surgery\%20Report\%20-\%20Final\% 20Draft.pdf 